\title{
Brief Communication: Maternal Plasma Autoantibodies Screening in Fetal Down Syndrome
}

\author{
Karol Charkiewicz, ${ }^{1}$ Monika Zbucka-Kretowska, ${ }^{2}$ Joanna Goscik, ${ }^{3}$ Slawomir Wolczynski, ${ }^{2}$ \\ Adam Lemancewicz, ${ }^{1}$ and Piotr Laudanski ${ }^{1}$ \\ ${ }^{1}$ Department of Perinatology and Obstetrics, Medical University of Bialystok, Marii Sklodowskiej-Curie 24a, 15-276 Bialystok, Poland \\ ${ }^{2}$ Department of Reproduction and Gynecological Endocrinology, Medical University of Bialystok, Marii Sklodowskiej-Curie 24a, \\ 15-276 Bialystok, Poland \\ ${ }^{3}$ Faculty of Computer Science, Bialystok University of Technology, Wiejska 45A, 15-351 Bialystok, Poland
}

Correspondence should be addressed to Piotr Laudanski; plauda@umb.edu.pl

Received 21 July 2015; Revised 14 January 2016; Accepted 27 January 2016

Academic Editor: Mario Clerici

Copyright (C) 2016 Karol Charkiewicz et al. This is an open access article distributed under the Creative Commons Attribution License, which permits unrestricted use, distribution, and reproduction in any medium, provided the original work is properly cited.

\begin{abstract}
Imbalance in the metabolites levels which can potentially be related to certain fetal chromosomal abnormalities can stimulate mother's immune response to produce autoantibodies directed against proteins. The aim of the study was to determine the concentration of 9000 autoantibodies in maternal plasma to detect fetal Down syndrome. Method. We performed 190 amniocenteses and found 10 patients with confirmed fetal Down syndrome (15th-18th weeks of gestation). For the purpose of our control we chose 11 women without confirmed chromosomal aberration. To assess the expression of autoantibodies in the blood plasma, we used a protein microarray, which allows for simultaneous determination of 9000 proteins per sample. Results. We revealed 213 statistically significant autoantibodies, whose expression decreased or increased in the study group with fetal Down syndrome. The second step was to create a classifier of Down syndrome pregnancy, which includes 14 antibodies. The predictive value of the classifier (specificity and sensitivity) is $100 \%$, classification errors, $0 \%$, cross-validation errors, $0 \%$. Conclusion. Our findings suggest that the autoantibodies may play a role in the pathophysiology of Down syndrome pregnancy. Defining their potential as biochemical markers of Down syndrome pregnancy requires further investigation on larger group of patients.
\end{abstract}

\section{Introduction}

The incidence of Down syndrome in the United States is estimated to be 1/732 live births [1]. This syndrome is a result of a chromosomal aberration characterized by extra chromosome 21 or a fragment thereof. In people with this aneuploidy, there is a high risk of congenital heart defects, gastroesophageal reflux syndrome, sleep apnoea, thyroid disease, and many other diseases [2].

Currently, the diagnosis of fetal Down syndrome is based on noninvasive (biochemical, genetic, and ultrasound) and invasive (amniocentesis and chorionic villous sampling) prenatal screening tests. Diagnostic efficacy of the invasive method in combination with genetic diagnostics is $99.8 \%$ and they rarely give false positive results. However, these methods carry a $1 \%$ risk of miscarriage or fetal damage [3]. A few years ago, scientists created a noninvasive prenatal test based on free fetal DNA (ffDNA) present in maternal blood. These tests have a low rate of false positives, which is only $0.5 \%$, but they are still very expensive [4-7]. Therefore, there is a need for new potential biomarkers of Down syndrome pregnancy which will provide enough data for a small percentage of false positive results that will not have to be confirmed by any invasive method. Emerging evidence suggests that reproductive events and successful pregnancy outcome are under the regulatory control of cytokines and bioactive lipids, such as sphingolipids, but their role in human normal and abnormal pregnancies is still largely undefined [8-12]. The status of 
selected cytokines and sphingolipids in plasma and amniotic fluid of patients with chromosomally abnormal pregnancies has already been described $[13,14]$. The current increased incidence of chromosomally abnormal pregnancy loss could depend on the aneuploidy that correlates with a disturbance of the release of some cytokines of placental perfusion and uterine contraction. The imbalanced levels of inflammatory cytokines in the case of abortion, preterm labour, premature rupture of the membranes, and fetal inflammatory response syndrome, where infection is absent, could be interpreted as a consequence of a genetic feature that results in fetus participating in the mechanism of its own distress, death, and expulsion [8]. Moreover, one of the more recent publications revealed that most of the deregulated genes (in Down syndrome) were involved in "angiogenesis," "inflammation mediated by cytokines and chemokines," "integrins," and "interleukins" signaling pathways, all of which can potentially lead to abnormal secretion of different molecules into mothers circulation [9]. It can be suggested that significant imbalance in the levels of different circulating metabolites in maternal blood can stimulate mother's immune response to produce autoantibodies directed against the abovementioned proteins. Therefore, measuring the expression of autoantibodies in pregnancies with fetal chromosomal abnormalities could lead to better understanding of the influence of Down syndrome on such pregnancy and possibly provide new biomarker(s) for noninvasive genetic testing.

\section{Material and Methods}

The study and control groups consisted of women who underwent routine amniocentesis between 15th and 18th week of gestation at the Department of Reproduction and Gynecological Endocrinology of the Medical University of Bialystok, Poland (recruitment between September 2012 and October 2013). We performed 190 amniocenteses throughout the recruitment period. We included only nonfebrile women without any chronic or acute diseases and excluded women taking any type of hormonal or anti-inflammatory treatment as well as those with vaginal and urinary tract symptoms that would suggest infection. We also excluded all pregnant women with previously diagnosed autoimmune diseases or with these diseases in their family history.

The study protocol was approved by the Local Ethics Committee of Medical University of Bialystok (Poland) (Approval number: R-I-002/36/2014). Signed informed consent was obtained from all participants involved in the study.

We collected $10 \mathrm{~mL}$ of peripheral blood into EDTA tubes from each patient after successfully performed amniocentesis. The blood was then centrifuged, plasma subsequently separated, and frozen at $-80^{\circ} \mathrm{C}$ temperature. After analyzing karyotype testing results, we chose 10 women with trisomy 21 fetuses into the study group and selected 11 healthy patients with uncomplicated pregnancies, who delivered healthy newborns at term for the control group.

To assess the expression of autoantibodies in the blood plasma we used the ProtoArray ${ }^{\bullet}$ Human Protein Microarray
5.1 (Invitrogen, USA), which allows for simultaneous determination of 9000 proteins per sample. This microarray was the first high-density microarray and it contains thousands of unique, full-length human proteins including kinases, phosphatases, GPCRs, nuclear receptors, and proteases, spotted in duplicate on a thin nitrocellulose coated glass slide with thickness 1 inch $\times 3$ inches. ProtoArray Human Protein Microarray version 5.1 contains over 9000 unique human proteins individually purified and arrayed under native conditions to maximize functionality.

A capture protein was first bound to a glass surface. After incubation with the sample, the target antibody was trapped on a solid surface. A second biotin-labeled detection antibody was then added, which can recognize a different isotope of the target autoantibody. The protein-autoantibodyantibody-biotin complex was then visualized through adding Streptavidin-Alexa Fluor 647 Conjugate and viewing with a laser scanner (GenePix 4100A). We also evaluated plasma C-reactive protein (CRP) levels using immunoturbidimetric method with the Multigent CRP Vario assay (detectable range was $0.2-480 \mathrm{mg} / \mathrm{L}$ ) detected on the ARCHITECT ci4100.

Computer analysis aiming at discovering proteins whose expression significantly differs in defined groups was performed using the Bioconductor limma package [15]. Preprocessing data with background correction and betweenarray normalization was the first step of the analysis. The purpose of this step was to transform the original data to enable comparing the results of multiple experiments (21 microarrays), obtaining approximate protein expression distribution across all of the arrays. We performed background correction using the normexp method [16], whereas for between-array normalization we applied the quantile method [17]. We determined the proteins undergoing statistically significant differential expression in the compared groups by fitting multiple linear models with the generalized least squares fitting method. Subsequently, we used the empirical Bayes method to rank the proteins in order of evidence for differential expression [18]. Significance level (alpha) equal to 0.05 and minimal absolute value of logged fold change (logarithm base 2) equal to 0.5 were fixed for all calculations. As the next step of the analysis, we validated the classification capability of the previously chosen proteins, showing differential expression and treated as features. Considering high probability of occurrence of similar expression profiles between the selected proteins, we used a feature selection procedure with the tools provided by the caret package [19]. Pearson correlation coefficient equal to at least 0.5 (in its absolute value) was taken as a threshold for considering features to be significantly correlated. After eliminating redundant features, we checked the classification accuracy of the remaining features using the Support Vector Machines classifier with the radial basis (Gaussian) kernel function and leave-one-out cross-validation procedure. The threshold value of the correlation coefficient was chosen to obtain the best classification accuracy with the smallest possible number of features. Features were standardized to zero mean and unit variance. Kernlab package [20] was employed for classification and validation. All of the computer analyses were conducted using the R software environment [21]. 
TABLE 1: Clinical characteristic of the patients.

\begin{tabular}{lcc}
\hline & $\begin{array}{c}\text { Group I, Down } \\
\text { syndrome } \\
\text { pregnancies } \\
(n=10)\end{array}$ & $\begin{array}{c}\text { Group II, } \\
\text { pregnancies } \\
\text { without Down } \\
\text { syndrome } \\
(n=11)\end{array}$ \\
\hline $\begin{array}{l}\text { Maternal age (median } \pm \text { SD) } \\
\text { Number of pregnancies } \\
\text { (median } \pm \text { SD) }\end{array}$ & $39.5 \pm 8.193$ & $38 \pm 8.799$ \\
$\begin{array}{l}\text { Gestational age at collecting of } \\
\text { samples in weeks } \\
\text { (median } \pm \text { SD) }\end{array}$ & $15.5 \pm 0.9189$ & $1 \pm 1.168$ \\
\hline
\end{tabular}

SD: standard deviation.

\section{Results}

Clinical characteristics of the patients are presented in Table 1. Statistical analysis of the expression of 9000 autoantibodies revealed that the expression of 213 autoantibodies (Table 2) is statistically significantly different (decreased or increased) when comparing the group with fetal Down syndrome and the control group. The next step of the analysis was to create a classifier providing the best possible discrimination between the studied groups. After eliminating redundant variables, as described in the previous section, 14 autoantibodies (Table 3) were chosen for further investigation. To test their predictive capability we built the Support Vector Machines classifier using the selected autoantibodies as features. The classification accuracy equal to $100 \%$ (i.e., cross-validation error equal to $0 \%$ ) was obtained using the leave-one-out crossvalidation technique and treating the selected autoantibodies as features.

The classifier is a set of autoantibodies whose concentrations do not correlate with each other, since each protein is independent of the other. These proteins together have greater sensitivity and specificity than each of them separately. Based on this set, it could be possible to create, in the future, a special software to estimate the risk of fetal Down syndrome by analyzing the concentrations of these autoantibodies in the mother's blood.

We did not find any statistically significant differences when we compared the plasma CRP concentrations between the study and control groups using Wilcoxon rank-sum test.

\section{Comment}

It is difficult to compare the results of our investigation to any other research, because of the lack of any articles about autoantibodies' profiling in maternal blood plasma of patients with fetal chromosomal abnormalities. Nevertheless, it is possible to associate some information available in the literature with our study results. There are potential explanations for the role of differentially expressed antibodies in the pathophysiology of Down syndrome pregnancy.

It is becoming more and more commonly acknowledged that fetal chromosomal aberration can cause imbalance in the metabolites levels in maternal blood. A number of studies describe inflammatory factors, hormones, and lipids potentially related with trisomy $21[8,9,13,14]$. Hence, our hypothesis is that significant changes in the blood metabolites profile of pregnant women diagnosed with fetal Down syndrome can stimulate mother's immune system and consequently lead to abnormal production of autoantibodies to maternal blood. The results of our investigation seem to confirm this hypothesis.

Initially, we compared the expression of all autoantibodies between the study and the control group. We revealed 213 statistically significant autoantibodies, whose expression decreased or increased in the group with fetal Down syndrome in comparison to the control group. Among these 213 proteins there were autoantibodies directed against well-known and described proteins in Down syndrome, for example, lamin-A/C [22], interleukin-1 receptor-associated kinase-like 2 [23], interleukin 17C [24], aminoadipate aminotransferase [25], calcium/calmodulin-dependent protein kinase kinase 1 [26], septin 4 (transcript variant 1) [27], serine/ threonine kinase [28], albumin [29], elastase 2B [30], glycine $\mathrm{N}$-methyltransferase [31], N-ethylmaleimide-sensitive factor attachment protein, gamma [32], dynamin 2 [33], tropomodulin-2 [34], interleukin-1 alpha [35], and selectin $\mathrm{P}$ ligand [36]. This finding may indirectly confirm the accuracy of our research. However, we believe that the classifier described in the present study is more interesting than just comparing individual autoantibodies. The classifier is of high diagnostic value and it indicates a potential new way of diagnosing fetal Down syndrome. The limitation of the study is a relatively small study group, but this is only a preliminary experiment and the results should be confirmed in a larger study population. In our next experiment, we expect to obtain enough high specificity and sensitivity of our classifier to eliminate the necessity of confirming the results by invasive methods.

From our study we excluded patients with symptoms of inflammation (only nonfebrile patients with negative CRP plasma levels were included in the study), which allows us to suspect that fluctuations of the autoantibodies' expression may be the result of fetal chromosomal aberration. Another limitation of the study is the lack of white blood count results; however, they are not routinely performed before each amniocentesis.

In the present study, we showed that selected autoantibodies could be potential biomarkers of Down syndrome pregnancies and could play a role in the pathology of trisomy 21. In the available literature there is still no relevant research focused on the role of autoantibodies in the pathogenesis of Down syndrome pregnancies. Therefore, it is difficult to definitely conclude on the variations in the levels of autoantibodies. However, due to the complexity of the pathomechanism responsible for fetal Down syndrome, further functional experiments should be performed.

\section{Competing Interests}

The authors declare that they have no competing interests. 
TABLE 2: The 213 statistically significant autoantibodies, whose expression decreased or increased in the group with fetal Down syndrome in comparison to the control group.

Name of autoantibody: antibody directed against the following proteins
Log FC (if there is negative value, it is decreased autoantibody expression in Down syndrome group versus control group; if there is positive value, it is increased autoantibody expression in Down syndrome group versus control group)

\begin{tabular}{|c|c|c|c|}
\hline 1 & $\begin{array}{l}\text { Recombining binding protein suppressor of hairless (Drosophila) } \\
\text { (RBPSUH), transcript variant 3, mRNA }\end{array}$ & 1,60 & 0,00 \\
\hline 2 & $\begin{array}{l}\text { Hematological and neurological expressed } 1 \text { (HN1), transcript variant } \\
3\end{array}$ & 1,55 & 0,01 \\
\hline 3 & Hepatitis $B$ virus $\mathrm{x}$ interacting protein (HBXIP) & 1,54 & 0,02 \\
\hline 4 & $\begin{array}{l}\text { Recombination signal binding protein for immunoglobulin kappa J } \\
\text { region (RBPJ), transcript variant } 4\end{array}$ & 1,45 & 0,00 \\
\hline 5 & Alcohol dehydrogenase, iron containing 1 (ADHFE1) & 1,41 & 0,01 \\
\hline 6 & Transcription factor CP2-like 1 (TFCP2L1) & 1,39 & 0,01 \\
\hline 7 & $\begin{array}{l}\text { WW domain containing oxidoreductase (WWOX), transcript variant } \\
3\end{array}$ & 1,33 & 0,03 \\
\hline 8 & $\begin{array}{l}\text { Angiogenin, ribonuclease, RNase A family, 5, mRNA (cDNA clone } \\
\text { MGC:61969 IMAGE:6453640), complete cds }\end{array}$ & 1,28 & 0,01 \\
\hline 9 & Ephrin receptor B1 (EPHB1) & 1,26 & 0,01 \\
\hline 10 & Spi-C transcription factor (Spi-1/PU.1 related) (SPIC) & 1,22 & 0,01 \\
\hline 11 & SUMO1 activating enzyme subunit 2 (SAE2) & 1,15 & 0,02 \\
\hline 12 & Family with sequence similarity 108 , member B1 (FAM108B1) & 1,11 & 0,00 \\
\hline 13 & SFRS protein kinase 1 (SRPK1) & 1,04 & 0,02 \\
\hline 14 & FGF6 recombinant human protein & 1,03 & 0,04 \\
\hline 15 & $\mathrm{BTB} / \mathrm{POZ}$ domain containing protein KCTD18 & 1,01 & 0,03 \\
\hline 16 & Zinc finger $\mathrm{CCHC}$ domain containing protein 8 & 1,00 & 0,04 \\
\hline 17 & Mediator of RNA polymerase II transcription subunit 22 & 0,99 & 0,01 \\
\hline 18 & Minichromosome maintenance complex component 2 (MCM2) & 0,99 & 0,03 \\
\hline 19 & ANKRD26-like family B member 1 & 0,98 & 0,00 \\
\hline 20 & Casein kinase 2, alpha prime polypeptide (CSNK2A2) & 0,97 & 0,01 \\
\hline 21 & $\begin{array}{l}\text { Lectin, Galactoside-Binding, Soluble, } 14 \text { (LGALS14), transcript } \\
\text { variant } 2\end{array}$ & 0,95 & 0,04 \\
\hline 22 & Stress 70 protein chaperone, microsome-associated, $60 \mathrm{kDa}(\mathrm{STCH})$ & 0,94 & 0,00 \\
\hline 23 & Suppressor of Ty 4 homolog 1 (S. cerevisiae) (SUPT4H1) & 0,94 & 0,00 \\
\hline 24 & Ephrin type-B receptor 2 & 0,93 & 0,01 \\
\hline 25 & WD repeat domain 69 (WDR69) & 0,92 & 0,02 \\
\hline 26 & Chromosome 6 open reading frame 206 (C6orf206) & 0,92 & 0,02 \\
\hline 27 & $\begin{array}{l}\text { v-akt murine thymoma viral oncogene homolog } 1 \text { (AKT1), transcript } \\
\text { variant } 3\end{array}$ & 0,91 & 0,04 \\
\hline 28 & Surfeit 5 (SURF5), transcript variant a & 0,90 & 0,01 \\
\hline 29 & $\begin{array}{l}\text { Calcium/calmodulin-dependent protein kinase (CaM kinase) II alpha } \\
\text { (CAMK2A), transcript variant } 1\end{array}$ & 0,90 & 0,01 \\
\hline 30 & P antigen family, member 2 (prostate associated) (PAGE2) & 0,88 & 0,03 \\
\hline 31 & Acyl-coenzyme A binding domain containing 7 (ACBD7) & 0,88 & 0,03 \\
\hline 32 & Chromosome 18 open reading frame 32 (C18orf32) & 0,87 & 0,04 \\
\hline 33 & $\begin{array}{l}\text { mRNA similar to oocyte-specific histone H1 (cDNA clone } \\
\text { MGC:50807 IMAGE:5742122), complete cds }\end{array}$ & 0,86 & 0,04 \\
\hline 34 & $\begin{array}{l}\text { Zinc finger protein SBZF3, mRNA (cDNA clone MGC:14334 } \\
\text { IMAGE:4298348), complete cds }\end{array}$ & 0,84 & 0,01 \\
\hline 35 & Protein DDI1 homolog 1 & 0,84 & 0,00 \\
\hline 36 & Proline-rich transmembrane protein 2 (PRRT2) & 0,83 & 0,05 \\
\hline
\end{tabular}


TABLE 2: Continued.

Name of autoantibody: antibody directed against the following proteins
Log FC (if there is negative value, it is decreased autoantibody expression in Down syndrome group versus control group; if there is positive value, it is increased autoantibody expression in Down syndrome group versus control group)

37 Mitogen-activated protein kinase kinase kinase 7 (MAP3K7), transcript variant B

0,82

0,04

38

Kv channel interacting protein 4 (KCNIP4), transcript variant 1

0,81

0,04

Nucleoredoxin

0,79

0,01

Hypothetical protein MGC40069 (MGC40069)

0,78

0,02

Chemokine (C-X-C motif) ligand 10, mRNA (cDNA clone MGC:13622 IMAGE:4274617), complete cds

0,77

0,04

Zinc finger, matrin type 5 (ZMAT5), transcript variant 1

0,77

0,00

Parvin, alpha (PARVA)

0,75

0,05

Interleukin-6

0,75

0,05

Eukaryotic elongation factor-2 kinase

0,75

0,04

Prefoldin subunit 4 (PFDN4)

0,74

0,02

Hypothetical protein FLJ10986 (FLJ10986)

0,74

0,03

Hypothetical protein MGC3020 (MGC3020)

0,73

0,03

Heat shock factor binding protein 1 (HSBP1)

0,73

0,02

Mitogen-activated protein kinase kinase kinase kinase 2 (MAP4K2)

0,72

0,03

Hypothetical protein MGC24103 (MGC24103)

0,72

0,02

Chromosome 7 open reading frame 36 (C7orf36)

0,72

0,05

Forkhead box P3 (FOXP3)

0,72

0,04

Ephrin receptor A1 (EPHA1)

0,71

0,02

ELL associated factor 1 (EAF1)

0,71

0,02

Exosome component 8 (EXOSC8)

0,70

0,02

Sialidase 4 (NEU4)

0,70

0,02

Activating signal cointegrator 1 complex subunit 2 (ASCC2)

0,70

0,03

Chemokine (C-C motif) ligand 13 (CCL13)

DNA-directed RNA polymerases I and III subunit RPAC1

0,69

0,00

0,69

0,01

Septin 4 (SEPT4), transcript variant 1

0,69

0,03

$62 \alpha$ serine/threonine kinase

0,69

0,02

Protein tyrosine phosphatase, receptor type, O (PTPRO), transcript variant 3

0,68

0,01

Nudix (nucleoside diphosphate linked moiety X) type motif 2

(NUDT2), transcript variant 1

0,68

0,03

Protein phosphatase 1, regulatory (inhibitor) subunit 2 pseudogene 9 (PPP1R2P9)

0,68

0,03

Septin 4 (SEPT4), transcript variant 3

0,68

0,04

Nuclear receptor coactivator 5

0,68

0,03

WD repeat domain 53 (WDR53)

0,67

0,02

RAR-related orphan receptor B (RORB)

0,67

0,00

Chromosome 8 open reading frame 22 (C8orf22)

0,66

0,02

Chromosome 21 open reading frame 25 (C21orf25)

0,64

0,02

Albumin (ALB)

0,64

0,03

Chromosome 10 open reading frame 83 (C10orf83)

0,63

0,01

StAR-related lipid transfer (START) domain containing 10 (STARD10)

0,63

0,04

Minichromosome maintenance complex component 7 (MCM7)

0,62

0,04 
TABLE 2: Continued.

Name of autoantibody: antibody directed against the following proteins

$\log \mathrm{FC}$ (if there is negative value, it is decreased autoantibody expression in Down syndrome group versus control group; if there is positive value, it is increased autoantibody expression in Down syndrome group versus control group)

\section{6}

Elastase 2B (ELA2B)

WD repeat domain $5 \mathrm{~B}$ (WDR5B)

Exosome component 5 (EXOSC5)

Spleen focus forming virus (SFFV) proviral integration oncogene spil (SPI1), mRNA

fms-related tyrosine kinase 3 ligand (FLT3LG)

Hemoglobin, gamma A (HBG1)

Leukocyte-associated immunoglobulin-like receptor 2 (LAIR2), transcript variant 1

Forkhead box P1 (FOXP1)

Polymerase (DNA-directed), delta 4 (POLD4)

Hypothetical protein AL133206 (LOC64744), mRNA

Ubiquitin-conjugating enzyme E2L 6 (UBE2L6), transcript variant 1

Protein kinase $\mathrm{C}$, beta 1 (PRKCB1), transcript variant 2

M-phase phosphoprotein 6 (MPHOSPH6)

Zinc finger protein 765 (ZNF765)

FtsJ homolog 1 (E. coli) (FTSJ1), transcript variant 1

Ring finger protein 128 (RNF128), transcript variant 1

TNFRSF1A/TNFRI/CD120a protein (His Tag)

Acid phosphatase 6, lysophosphatidic (ACP6)

Nucleophosmin (nucleolar phosphoprotein B23, numatrin) (NPM1)

Kelch domain containing 3 (KLHDC3), mRNA

$\mathrm{N}(6)$-Adenine-specific DNA methyltransferase 1

RAB4A, member RAS oncogene family (RAB4A)

Zinc finger protein 396 (ZNF396), mRNA

kinesin family member 3A (KIF3A)

Poly(rC)-binding protein 2

WD repeat and FYVE domain containing 3 (WDFY3), transcript variant 3

Glycine N-methyltransferase (GNMT)

Histone $\mathrm{H} 2 \mathrm{~B}$ type $1-\mathrm{H}$

Tumor necrosis factor, alpha-induced protein 8-like 1 (TNFAIP8L1)

BRCA2 and CDKN1A interacting protein (BCCIP)

DnaJ (Hsp40) homolog, subfamily B, member 11 (DNAJB11)

Lamin-A/C

Seven in absentia homolog 1 (Drosophila) (SIAH1), transcript variant 2, mRNA

Ninjurin 2 (NINJ2)

Trypsin-2

PREDICTED (uORF:IOH62458 RFU:1604.5)

Chromosome 20 open reading frame 39 (C20orf39)

Dual specificity mitogen-activated protein kinase kinase 3

Polymerase (RNA) III (DNA directed) polypeptide C (62 kDa) (POLR3C)

\begin{tabular}{|c|c|}
\hline 0,62 & 0,04 \\
\hline 0,61 & 0,02 \\
\hline 0,61 & 0,04 \\
\hline 0,59 & 0,04 \\
\hline 0,59 & 0,03 \\
\hline 0,59 & 0,03 \\
\hline 0,59 & 0,05 \\
\hline 0,58 & 0,03 \\
\hline 0,58 & 0,04 \\
\hline 0,58 & 0,02 \\
\hline 0,57 & 0,03 \\
\hline 0,57 & 0,04 \\
\hline 0,57 & 0,01 \\
\hline 0,56 & 0,01 \\
\hline 0,56 & 0,04 \\
\hline 0,56 & 0,02 \\
\hline 0,55 & 0,05 \\
\hline 0,55 & 0,02 \\
\hline 0,55 & 0,02 \\
\hline 0,55 & 0,03 \\
\hline 0,55 & 0,05 \\
\hline 0,54 & 0,03 \\
\hline 0,54 & 0,02 \\
\hline 0,53 & 0,04 \\
\hline 0,53 & 0,05 \\
\hline 0,53 & 0,05 \\
\hline 0,53 & 0,01 \\
\hline 0,53 & 0,04 \\
\hline 0,52 & 0,02 \\
\hline 0,52 & 0,02 \\
\hline 0,52 & 0,05 \\
\hline 0,51 & 0,04 \\
\hline 0,50 & 0,05 \\
\hline$-0,50$ & 0,04 \\
\hline$-0,50$ & 0,02 \\
\hline$-0,51$ & 0,04 \\
\hline$-0,52$ & 0,03 \\
\hline$-0,52$ & 0,04 \\
\hline$-0,52$ & 0,03 \\
\hline
\end{tabular}

$P$ value 0,04

03

03

02

04

04

02

02

02

03

02

05

05

04

02

04

05

04

03

04 
TABLE 2: Continued.

Name of autoantibody: antibody directed against the following proteins
Log FC (if there is negative value, it is decreased autoantibody expression in Down syndrome group versus control group; if there is positive value, it is increased autoantibody expression in Down syndrome group versus control group)

$-0,52$

Interleukin-1 receptor-associated kinase-like 2

$-0,53$

$-0,53$

$-0,53$

$-0,54$

$-0,54$

$-0,55$

$-0,55$

$-0,56$

$-0,56$

$-0,57$

$-0,57$

$-0,57$

$-0,58$

$-0,58$

$-0,58$

$-0,58$

$-0,58$

$-0,59$

$-0,59$

$-0,59$

$-0,60$

$-0,60$

$-0,60$

$-0,61$

$-0,61$

$-0,62$

$-0,63$

$-0,64$

$-0,64$

$-0,64$

$-0,65$

$-0,65$

$-0,65$

$-0,65$

$-0,66$

$-0,66$

$-0,67$

$-0,68$

0,02

$P$ value

0,05

0,04

0,04

0,03

0,02

0,02

0,02

0,05

0,05

0,02

0,04

0,03

0,04

0,04

0,02

0,01

0,02

0,02

0,05

0,04

0,02

0,05

0,01

0,04

0,04

0,04

0,01

0,03

0,04

0,01

0,02

0,01

0,03

0,01

0,05

0,05

0,02

0,04 
TABLE 2: Continued.

Name of autoantibody: antibody directed against the following proteins $\log$ FC (if there is negative value, it is decreased autoantibody expression in Down syndrome group versus control group; if there is positive value, it is increased autoantibody expression in Down syndrome group versus control $P$ value group)

\begin{tabular}{|c|c|c|c|}
\hline 154 & $\begin{array}{l}\text { Mitogen-activated protein kinase kinase } 3 \text { (MAP2K3), transcript } \\
\text { variant B }\end{array}$ & $-0,68$ & 0,00 \\
\hline 155 & Aminoadipate aminotransferase (AADAT) & $-0,69$ & 0,02 \\
\hline 156 & $\begin{array}{l}\text { DCP1 decapping enzyme homolog B (S. cerevisiae), mRNA (cDNA } \\
\text { clone MGC:44405 IMAGE:5296928), complete cds }\end{array}$ & $-0,69$ & 0,02 \\
\hline 157 & Calcium/calmodulin-dependent protein kinase kinase 1 & $-0,69$ & 0,04 \\
\hline 158 & $\begin{array}{l}\text { CD40 molecule, TNF receptor superfamily member } 5 \text { (CD } 40) \text {, } \\
\text { transcript variant } 1\end{array}$ & $-0,69$ & 0,00 \\
\hline 159 & Signal peptide peptidase 3 (UNQ1887) & $-0,69$ & 0,00 \\
\hline 160 & MLCK protein (MLCK) & $-0,70$ & 0,04 \\
\hline 161 & $\begin{array}{l}\text { Vacuolar protein sorting } 24 \text { homolog (S. cerevisiae) (VPS24), } \\
\text { transcript variant } 2\end{array}$ & $-0,70$ & 0,02 \\
\hline 162 & LY6/PLAUR domain containing 1 (LYPD1), transcript variant 1 & $-0,71$ & 0,02 \\
\hline 163 & Hypothetical protein FLJ31153 (FLJ31153), mRNA & $-0,71$ & 0,05 \\
\hline 164 & Fas apoptotic inhibitory molecule (FAIM), transcript variant 4 & $-0,71$ & 0,05 \\
\hline 165 & ATR interacting protein (TREX1) & $-0,72$ & 0,03 \\
\hline 166 & EP300-interacting inhibitor of differentiation 3 & $-0,72$ & 0,04 \\
\hline 167 & lin-7 homolog A (C, elegans) (LIN7A) & $-0,73$ & 0,02 \\
\hline 168 & Zeta-chain (TCR) associated protein kinase $70 \mathrm{kDa}$ (ZAP70) & $-0,73$ & 0,05 \\
\hline 169 & $\begin{array}{l}\text { Deleted in a mouse model of primary ciliary dyskinesia } \\
\text { (RP11-529I10,4) }\end{array}$ & $-0,74$ & 0,04 \\
\hline 170 & $\begin{array}{l}\text { N-ethylmaleimide-sensitive factor attachment protein, gamma } \\
\text { (NAPG) }\end{array}$ & $-0,74$ & 0,02 \\
\hline 171 & Dynamin $2(\mathrm{DNM} 2)$ & $-0,74$ & 0,00 \\
\hline 172 & Ribosomal protein L12 (RPL12) & $-0,74$ & 0,01 \\
\hline 173 & CD300 molecule-like family member g (CD300LG) & $-0,75$ & 0,00 \\
\hline 174 & 4-Hydroxyphenylpyruvate dioxygenase & $-0,75$ & 0,04 \\
\hline 175 & Nuclease EXOG, mitochondrial & $-0,76$ & 0,01 \\
\hline 176 & Nuclear receptor coactivator 4 (NCOA4) & $-0,76$ & 0,02 \\
\hline 177 & Mitogen-activated protein kinase kinase kinase 14 & $-0,77$ & 0,02 \\
\hline 178 & $\begin{array}{l}\text { Chromosome } 18 \text { open reading frame } 1 \text { (C18orf1), transcript variant } \mathrm{c} 2 \text {, } \\
\text { mRNA }\end{array}$ & $-0,77$ & 0,04 \\
\hline 179 & Growth arrest-specific 2 (GAS2), transcript variant 2 & $-0,78$ & 0,01 \\
\hline 180 & Transducin (beta)-like 1X-linked (TBL1X) & $-0,79$ & 0,03 \\
\hline 181 & Bone morphogenetic protein receptor, type IB (BMPR1B) & $-0,79$ & 0,03 \\
\hline 182 & Tropomodulin-2 & $-0,79$ & 0,03 \\
\hline 183 & Calcium binding protein 39 (CAB39) & $-0,81$ & 0,03 \\
\hline 184 & Selectin P ligand (SELPLG) & $-0,81$ & 0,01 \\
\hline 185 & $\begin{array}{l}\text { Neutrophil cytosolic factor } 2 \text { ( } 65 \mathrm{kDa} \text {, chronic granulomatous disease, } \\
\text { autosomal 2) (NCF2) }\end{array}$ & $-0,82$ & 0,02 \\
\hline 186 & Retinoic acid receptor, beta (RARB), transcript variant 2 & $-0,82$ & 0,01 \\
\hline 187 & Potassium voltage-gated channel subfamily E member 1 & $-0,82$ & 0,02 \\
\hline 188 & Interleukin-1 alpha & $-0,82$ & 0,01 \\
\hline 189 & Nucleoporin-like 1 (NUPL1), transcript variant 1 & $-0,82$ & 0,01 \\
\hline 190 & HIG1 domain family, member 2A (HIGD2A) & $-0,82$ & 0,03 \\
\hline 191 & Pleiotropic regulator 1 (PRL1 homolog, Arabidopsis) (PLRG1) & $-0,83$ & 0,01 \\
\hline 192 & $\begin{array}{l}\text { Coiled-coil domain containing 76, mRNA (cDNA clone MGC: } 87928 \\
\text { IMAGE:5104751), complete cds }\end{array}$ & $-0,83$ & 0,02 \\
\hline
\end{tabular}


TABLE 2: Continued.

Name of autoantibody: antibody directed against the following proteins
Log FC (if there is negative value, it is decreased autoantibody expression in Down syndrome group versus control group; if there is positive value, it is increased autoantibody expression in Down syndrome group versus control group)

\begin{tabular}{|c|c|c|c|}
\hline 193 & $\begin{array}{l}\text { GTPase activating protein (SH3 domain) binding protein } 1 \text { (G3BP1), } \\
\text { transcript variant } 2\end{array}$ & $-0,84$ & 0,03 \\
\hline 194 & Golgi SNAP receptor complex member 1 (GOSR1), transcript variant 1 & $-0,84$ & 0,04 \\
\hline 195 & Phosphoglucomutase 2 & $-0,84$ & 0,03 \\
\hline 196 & RAS-like, family 11, member B (RASL11B) & $-0,86$ & 0,05 \\
\hline 197 & Proteasome subunit alpha type 1 & $-0,86$ & 0,04 \\
\hline 198 & MAP3K12-binding inhibitory protein 1 & $-0,89$ & 0,00 \\
\hline 199 & Zinc finger, DHHC-type containing 11 (ZDHHC11) & $-0,91$ & 0,02 \\
\hline 200 & Moesin (MSN) & $-0,92$ & 0,01 \\
\hline 201 & Guanine nucleotide exchange factor DBS & $-0,92$ & 0,01 \\
\hline 202 & Chromosome 13 open reading frame 16 (C13orf16) & $-0,92$ & 0,04 \\
\hline 203 & Regulator of G-protein signaling 14 (RGS14) & $-0,97$ & 0,03 \\
\hline 204 & $\begin{array}{l}\text { LSM4 homolog, U6 small nuclear RNA associated (S. cerevisiae) } \\
\text { (LSM4) }\end{array}$ & $-1,01$ & 0,03 \\
\hline 205 & Fibronectin type III domain containing 4 (FNDC4) & $-1,09$ & 0,00 \\
\hline 206 & Myosin light chain kinase 2, skeletal muscle (MYLK2) & $-1,12$ & 0,03 \\
\hline 207 & HCG3 gene (HCG3) & $-1,15$ & 0,03 \\
\hline 208 & $\begin{array}{l}\text { cAMP responsive element modulator (CREM), transcript variant } 20 \text {, } \\
\text { mRNA, }\end{array}$ & $-1,31$ & 0,03 \\
\hline 209 & $\begin{array}{l}\text { TAF6 RNA polymerase II, TATA box binding protein (TBP) } \\
\text { associated factor, } 80 \mathrm{kDa} \text { (TAF6), transcript variant } 1\end{array}$ & $-1,43$ & 0,00 \\
\hline 210 & tec protein tyrosine kinase (TEC) & $-1,76$ & 0,03 \\
\hline 211 & Enolase 3 (beta, muscle) (ENO3) & $-2,02$ & 0,02 \\
\hline 212 & Chromosome 19 open reading frame 33 (C19orf33) & $-2,40$ & 0,02 \\
\hline 213 & $26 \mathrm{~S}$ proteasome non-ATPase regulatory subunit 7 & $-2,87$ & 0,02 \\
\hline
\end{tabular}

TABLE 3: The 14 autoantibodies building the classifier.

\begin{tabular}{|c|c|c|}
\hline & Antibody directed against the following proteins & Ultimate ORF ID/catalog number \\
\hline 1 & Retinoic acid receptor-beta (RARB) transcript variant 2 & Hs Ref:NM_016152.2 uORF:IOH36705 RFU:23189.6 \\
\hline 2 & Phosphoglucomutase 2-like 1 (PGM2L1) & Hs MGC:BC059360.1 uORF:IOH29131 RFU:29573.42 \\
\hline 3 & Hepatitis $\mathrm{B}$ virus $\mathrm{x}$ interacting protein (HBXIP) & Hs Ref:NM_006402.2 uORF:IOH40860 RFU:21469.91 \\
\hline 4 & Hypothetical protein MGC24103 (MGC24103) & Hs MGC:NM_152576.1 uORF:IOH23047 RFU:19377.96 \\
\hline 5 & $\begin{array}{l}\text { cAMP responsive element modulator (CREM), transcript variant } \\
20, \text { mRNA }\end{array}$ & Hs Ref:NM_183012.1 uORF:IOH53457 RFU:0 \\
\hline 6 & Transient receptor potential cation channel subfamily $\mathrm{M}$ member 3 & Hs MGC:BC022454.2 uORF:IOH10977 RFU:4933.46 \\
\hline 7 & 4-Hydroxyphenylpyruvate dioxygenase & Hs Ref:NM_002150.1 uORF:IOH14718 RFU:30044.88 \\
\hline 8 & Chromosome 20 open reading frame 71 (C20orf71) & Hs MGC:BC066354.1 uORF:IOH40076 RFU:14763.08 \\
\hline 9 & TNFSF10/APO2L/TRAIL/CD253 protein (native) & Hs Ref:NP_003801.1 CAT_10409-HNAE-25 RFU:28.23 \\
\hline 10 & $\mathrm{Kv}$ channel interacting protein 4 (KCNIP4), transcript variant 1 & Hs Ref:NM_025221.4 uORF:IOH21934 RFU:27826.87 \\
\hline 11 & Exosome component 5 (EXOSC5) & Hs MGC:BC007742.1 uORF:IOH6517 RFU:29914.87 \\
\hline 12 & $\begin{array}{l}\text { Golgi SNAP receptor complex member } 1 \text { (GOSR1), transcript } \\
\text { variant } 1\end{array}$ & Hs Ref:NM_004871.2 uORF:IOH45920 RFU:29968.08 \\
\hline 13 & Chromosome 18 open reading frame 32 (C18orf32) & Hs MGC:BC022357.1 uORF:IOH14149 RFU:28760.06 \\
\hline 14 & Proline-rich transmembrane protein 2 (PRRT2) & Hs MGC:BC053594.1 uORF:IOH28968 RFU:10273.9 \\
\hline
\end{tabular}




\section{Acknowledgments}

This work was supported by Grant no. N N407 598338 from the National Science Center and by the funds of The Leading National Scientific Center, Medical University of Bialystok, Poland.

\section{References}

[1] S. L. Sherman, E. G. Allen, L. H. Bean, and S. B. Freeman, "Epidemiology of Down syndrome," Mental Retardation and Developmental Disabilities Research Reviews, vol. 13, no. 3, pp. 221-227, 2007.

[2] S. Ghosh, E. Feingold, and S. K. Dey, "Etiology of down syndrome: evidence for consistent association among altered meiotic recombination, nondisjunction, and maternal age across populations," American Journal of Medical Genetics A, vol. 149, no. 7, pp. 1415-1420, 2009.

[3] P. A. Benn, J. Ying, T. Beazoglou, and J. F. X. Egan, "Estimates for the sensitivity and false-positive rates for second trimester serum screening for Down syndrome and trisomy 18 with adjustment for cross-identification and double-positive results," Prenatal Diagnosis, vol. 21, no. 1, pp. 46-51, 2001.

[4] R. W. K. Chiu, R. Akolekar, Y. W. L. Zheng et al., "Non-invasive prenatal assessment of trisomy 21 by multiplexed maternal plasma DNA sequencing: large scale validity study," British Medical Journal, vol. 342, article c7401, 2011.

[5] M. Ehrich, C. Deciu, T. Zwiefelhofer et al., "Noninvasive detection of fetal trisomy 21 by sequencing of DNA in maternal blood: a study in a clinical setting," American Journal of Obstetrics and Gynecology, vol. 204, no. 3, pp. 205.el-205.ell, 2011.

[6] A. B. Sparks, E. T. Wang, C. A. Struble et al., "Selective analysis of cell-free DNA in maternal blood for evaluation of fetal trisomy," Prenatal Diagnosis, vol. 32, no. 1, pp. 3-9, 2012.

[7] G. E. Palomaki, E. M. Kloza, G. M. Lambert-Messerlian et al., "DNA sequencing of maternal plasma to detect Down syndrome: an international clinical validation study," Genetics in Medicine, vol. 13, no. 11, pp. 913-920, 2011.

[8] F. Vesce, C. Scapoli, G. Giovannini et al., "Cytokine imbalance in pregnancies with fetal chromosomal abnormalities," Human Reproduction, vol. 17, no. 3, pp. 803-808, 2002.

[9] V. Costa, L. Sommese, A. Casamassimi et al., "Impairment of circulating endothelial progenitors in Down syndrome," $B M C$ Medical Genomics, vol. 3, article 40, 2010.

[10] R. O. Bahado-Singh, R. Akolekar, R. Mandal et al., "Metabolomic analysis for first-trimester Down syndrome prediction," American Journal of Obstetrics and Gynecology, vol. 208, no. 5, pp. 371.el-371.e8, 2013.

[11] P. Laudanski, A. Lemancewicz, P. Pierzynski, M. Akerlund, and T. Laudanski, "Decreased serum level of macrophage inflammatory chemokine-3 $\beta /$ CCL19 in preterm labor and delivery," European Journal of Obstetrics Gynecology and Reproductive Biology, vol. 124, no. 1, pp. 23-26, 2006.

[12] M. Kuzmicki, B. Telejko, A. Zonenberg et al., "Circulating pro- and anti-inflammatory cytokines in Polish women with gestational diabetes," Hormone and Metabolic Research, vol. 40, no. 8, pp. 556-560, 2008.

[13] P. Laudanski, M. Zbucka-Kretowska, K. Charkiewicz, S. Wolczynski, D. Wojcik, and R. Charkiewicz, "Maternal plasma and amniotic fluid chemokines screening in fetal down syndrome," Mediators of Inflammation, vol. 2014, Article ID 835837, 10 pages, 2014.
[14] K. Charkiewicz, A. Blachnio-Zabielska, M. Zbucka-Kretowska, S. Wolczynski, and P. Laudanski, "Maternal plasma and amniotic fluid sphingolipids profiling in fetal Down syndrome," PLoS ONE, vol. 10, no. 5, Article ID e0127732, 2015.

[15] G. K. Smyth, "Limma: linear models for microarray data," in Bioinformatics and Computational Biology Solutions Using R and Bioconductor, Statistics for Biology and Health, pp. 397-420, Springer, New York, NY, USA, 2005.

[16] J. D. Silver, M. E. Ritchie, and G. K. Smyth, "Microarray background correction: maximum likelihood estimation for the normal-exponential convolution," Biostatistics, vol. 10, no. 2, pp. 352-363, 2009

[17] G. K. Smyth and T. Speed, "Normalization of cDNA microarray data," Methods, vol. 31, no. 4, pp. 265-273, 2003.

[18] G. K. Smyth, "Linear models and empirical bayes methods for assessing differential expression in microarray experiments," Statistical Applications in Genetics and Molecular Biology, vol. 3, article 3, 2004.

[19] 2015, http://cran.r-project.org/package $=$ caret.

[20] A. Karatzoglou, "Kernlab—an S4 package for Kernel methods in R," Journal of Statistical Software, vol. 11, no. 9, pp. 1-20, 2004.

[21] 2015, https://www.r-project.org/.

[22] C. A. Hoeffer, A. Dey, N. Sachan et al., "The Down syndrome critical region protein RCAN1 regulates long-term potentiation and memory via inhibition of phosphatase signaling," The of Neuroscience, vol. 27, no. 48, pp. 13161-13172, 2007.

[23] J. Y. Lee, H. J. Lee, E. J. Lee et al., "Down syndrome candidate region-1 protein interacts with Tollip and positively modulates interleukin-1 receptor-mediated signaling," Biochimica et Biophysica Acta-General Subjects, vol. 1790, no. 12, pp. 1673-1680, 2009.

[24] G. Tsilingaridis, T. Yucel-Lindberg, and T. Modéer, "T-helperrelated cytokines in gingival crevicular fluid from adolescents with Down syndrome," Clinical Oral Investigations, vol. 16, no. 1, pp. 267-273, 2012.

[25] Y. Hibaoui, I. Grad, A. Letourneau et al., "Modelling and rescuing neurodevelopmental defect of Down syndrome using induced pluripotent stem cells from monozygotic twins discordant for trisomy 21," EMBO Molecular Medicine, vol. 6, no. 2, pp. 259-277, 2014.

[26] R. J. Siarey, A. Kline-Burgess, M. Cho et al., "Altered signaling pathways underlying abnormal hippocampal synaptic plasticity in the Ts65Dn mouse model of Down syndrome," Journal of Neurochemistry, vol. 98, no. 4, pp. 1266-1277, 2006.

[27] J. H. Sitz, K. Baumgärtel, B. Hämmerle et al., "The down syndrome candidate dual-specificity tyrosine phosphorylationregulated kinase $1 \mathrm{~A}$ phosphorylates the neurodegenerationrelated septin 4," Neuroscience, vol. 157, no. 3, pp. 596-605, 2008.

[28] J. Guimerá, C. Casas, C. Pucharcòs et al., "A human homologue of Drosophila minibrain (MNB) is expressed in the neuronal regions affected in Down syndrome and maps to the critical region," Human Molecular Genetics, vol. 5, no. 9, pp. 1305-1310, 1996.

[29] A. Kolialexi, G. T. Tsangaris, N. Papantoniou et al., "Application of proteomics for the identification of differentially expressed protein markers for Down syndrome in maternal plasma," Prenatal Diagnosis, vol. 28, no. 8, pp. 691-698, 2008.

[30] H. Chen, R. Chrast, C. Rossier, M. A. Morris, M. D. Lalioti, and S. E. Antonarakis, "Cloning of 559 potential exons of genes of human chromosome 21 by exon trapping," Genome Research, vol. 6, no. 8, pp. 747-760, 1996. 
[31] R. Obeid, K. Hartmuth, W. Herrmann et al., "Blood biomarkers of methylation in Down syndrome and metabolic simulations using a mathematical model," Molecular Nutrition and Food Research, vol. 56, no. 10, pp. 1582-1589, 2012.

[32] B. C. Yoo, N. Cairns, M. Fountoulakis, and G. Lubec, "Synaptosomal proteins, beta-soluble N-ethylmaleimide-sensitive factor attachment protein (Beta-SNAP), gamma-SNAP and synaptotagmin I in brain of patients with Down syndrome and Alzheimer's disease," Dementia and Geriatric Cognitive Disorders, vol. 12, no. 3, pp. 219-225, 2001.

[33] H. E. Lockstone, L. W. Harris, J. E. Swatton, M. T. Wayland, A. J. Holland, and S. Bahn, "Gene expression profiling in the adult Down syndrome brain," Genomics, vol. 90, no. 6, pp. 647-660, 2007.

[34] Y. Sun, M. Dierssen, N. Toran, D. D. Pollak, W.-Q. Chen, and G. Lubec, "A gel-based proteomic method reveals several protein pathway abnormalities in fetal Down syndrome brain," Journal of Proteomics, vol. 74, no. 4, pp. 547-557, 2011.

[35] A. Khocht, K. Heaney, M. Janal, and B. Turner, "Association of interleukin-1 polymorphisms with periodontitis in Down syndrome," Journal of oral science, vol. 53, no. 2, pp. 193-202, 2011.

[36] R. W. Old, F. Crea, W. Puszyk, and M. A. Hultén, "Candidate epigenetic biomarkers for non-invasive prenatal diagnosis of Down syndrome," Reproductive BioMedicine Online, vol. 15, no. 2, article no. 2826, pp. 227-235, 2007. 


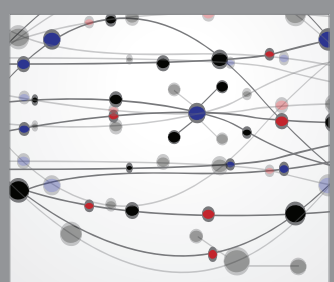

The Scientific World Journal
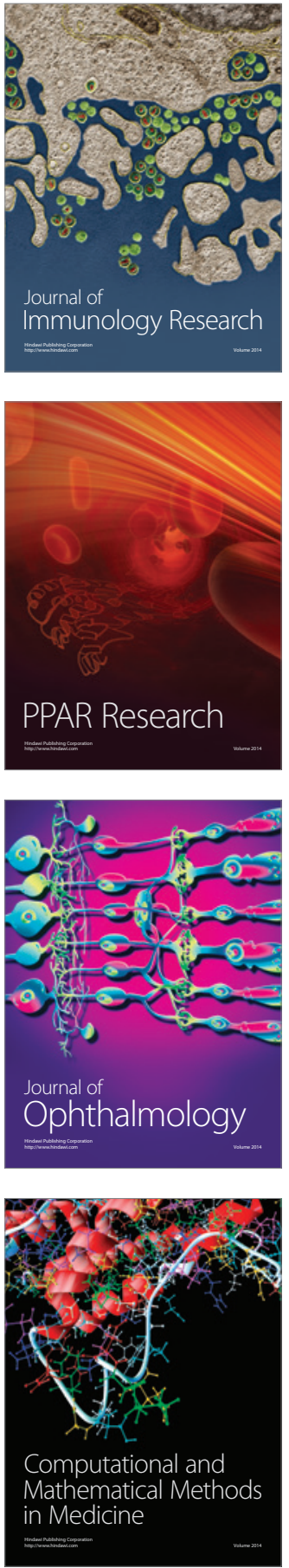

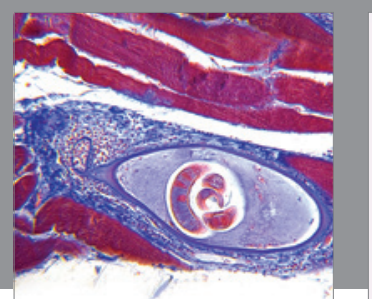

Gastroenterology Research and Practice

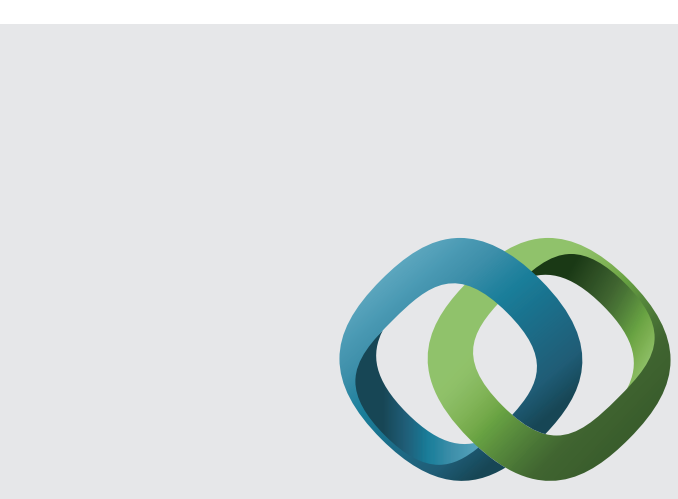

\section{Hindawi}

Submit your manuscripts at

http://www.hindawi.com
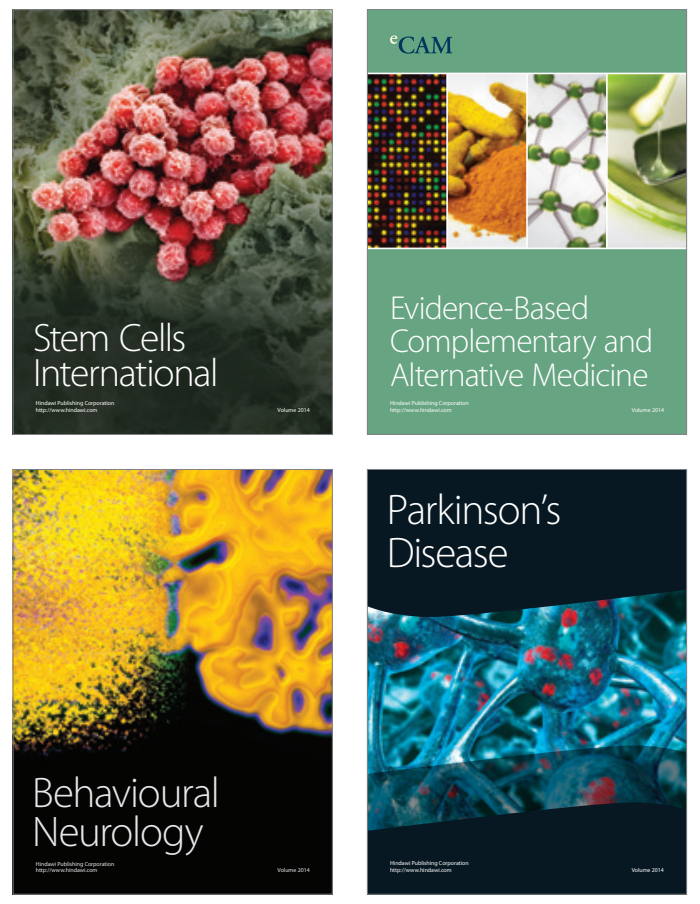
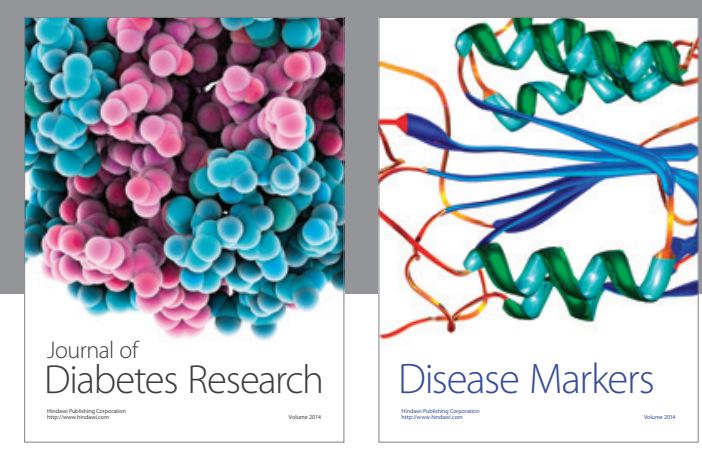

Disease Markers
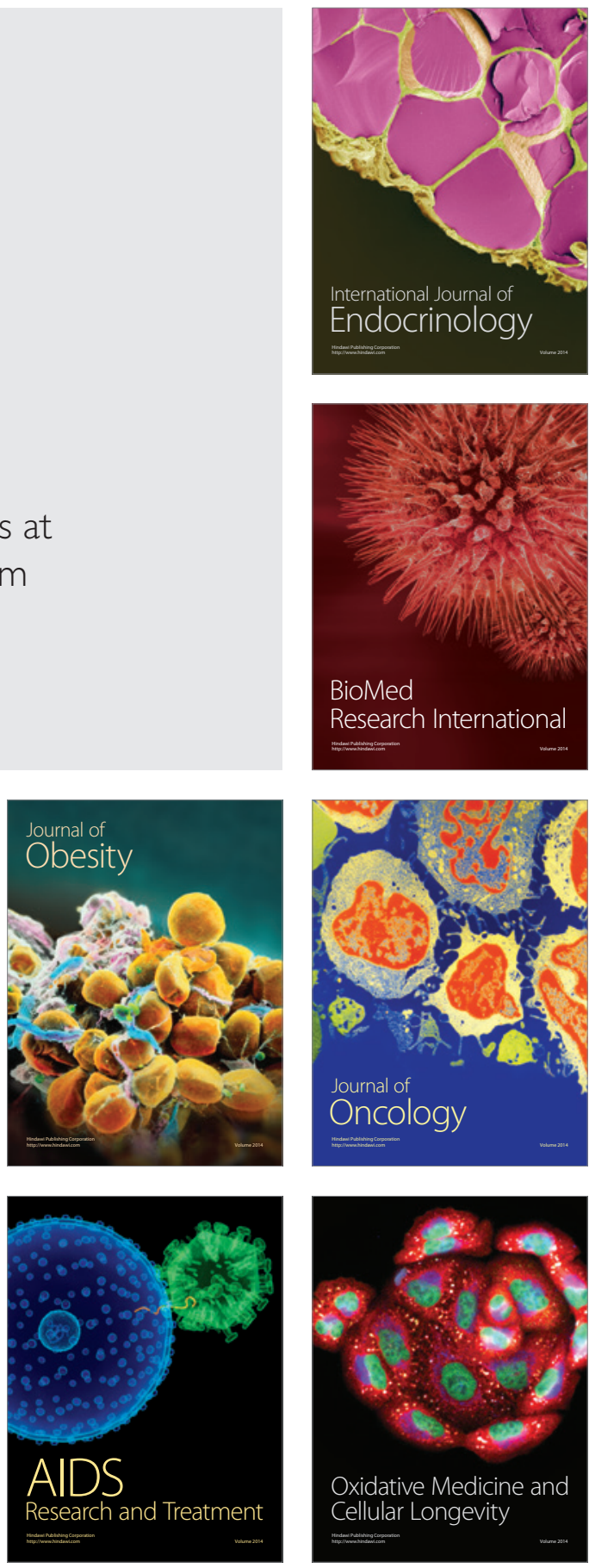